\title{
Stabilization Policy and Inflation
}

I

NFLATION, caused by an excessive rise in total spending, has been a serious national problem since the mid-Sixties. The monetary and fiscal actions of the past two years have been successful in moderating the surge in total spending, and initial adjustments thereto were manifested by reduced real output. More recent adjustments apparently have included a decline in the rate of price increase.

An immediate consequence of the battle against inflation has been insufficient total spending to absorb the growing labor force and plant capacity. But success in correcting established inflation has always been costly. If the growth of total demand for goods and services is restrained to a reasonable rate, output and employment growth will gradually accelerate as inflationary forces recede.

Two strategic questions for stabilization policy in the immediate future are: what is an appropriate rate of spending growth? and what rate of growth in money will foster this spending growth? This Bank has estimated that a 3 per cent rate of increase in money will provide about a 4.5 per cent rate of spending growth a year from now, while a 5 per cent rate of increase in money will provide about a 6.5 per cent rate of spending growth. ${ }^{1}$

\section{Monctary Actions}

Monetary actions have been a major factor in moderating the growth of total spending in 1969 and 1970 , just as in 1966 and 1967. The money stock did not grow from April 1966 to January 1967 and then expanded at about a 7 per cent annual rate in 1967 . Similarly, eight months of little expansion in the money stock from June 1969 to February 1970 have been followed by about a 6 per cent growth rate in the money stock since February. In early 1967, total spending growth slowed markedly to a 3.6 per cent annual rate in the first half of the year. Similarly, after autumn 1969, total spending growth slowed to a 4.1 per cent rate. In both instances, monetary authorities reacted to the slowdown by shifting to a relatively less restrictive monetary policy, with a view

1See "A Monetarist Model for Economic Stabilization," this Review (April 1970), pp. 7+25; and "Economic Slowdown and Stabilization Policy, this Review (September 1970), pp. 6 and 7 .

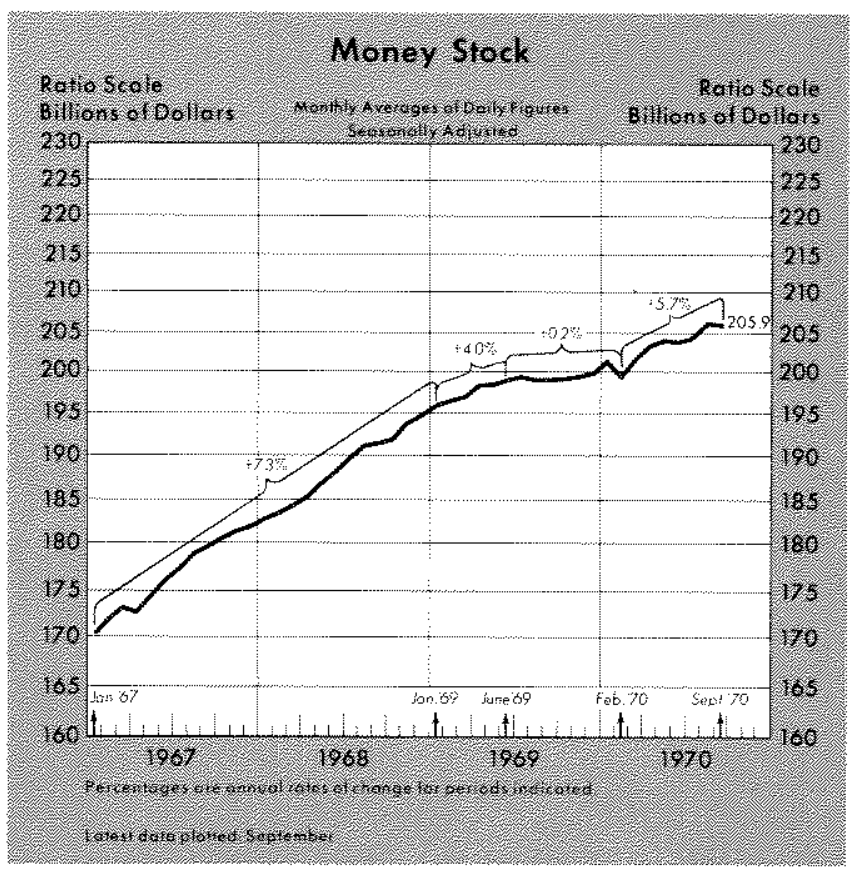

to avoiding inordinate restraint on total spending and output.

The more rapid growth of the money stock since February 1970 has been fostered by increases in Federal Reserve credit and member bank reserves and has been accompanied by rapid growth in time deposits. Total Federal Reserve credit grew at a 9 per cent annual rate from February to September, compared with a 2.7 per cent rate from January 1969 to February 1970. Total member bank reserves grew at a 9.5 per cent annual rate from February to September 1970 .

Time deposits at commercial banks have increased rapidly in 1970, because banks have been better able to compete for funds than in 1969. Certain interest rate ceilings were relaxed in January and completely suspended on 30- to 89-day large CD's in June, and short-term market interest rates have declined. Time deposits grew at a 12 per cent annual rate from January to June and at a 35 per cent rate from June to September. About half of the increase in time deposits since February of this year has been in the form of large negotiable certificates of deposit, representing largely a reintermediation of funds previously flowing through nonbank channels. 
The inflow of time deposits to commercial banks has not been at the expense of savings flows into nonbank financial intermediaries. Net savings flows to nonbank financial intermediaries have increased rapidly in 1970 compared with 1969. Savings and loan shares grew at an 8 per cent amual rate in the first eight months of 1970 compared with 2.6 per cent in 1969. Mutual savings bank deposits increased at a 6.3 per cent annual rate in 1970 compared with 3.9 per cent in 1969.

Short-term market interest rates have declined in 1970 , because of more rapid monetary expansion and slower growth of total credit demand. Threemonth Treasury bill rates declined from 7.87 per cent in January to 5.84 per cent in early October. The decline in short-term market interest rates relative to the discount rate, together with the greater ability of banks to attract time deposit funds, has induced member banks to reduce their borrowings at the Federal Reserve from about $\$ 900$ million last spring to about $\$ 500$ million in late September and early October.

In contrast to short-term interest rates, yields on long-term corporate bonds have changed little on balance in 1970 , because of continued heavy demands for funds relative to the supply. Interest rates on highest grade seasoned corporate bonds; after reaching a peak of 8.60 per cent in mid-1970, declined to about 8 per cent in early October, about the same as at the beginning of the year.

\section{Total Spending and Ontwit}

Monetary and fiscal restraint in 1969 and 1970 have been successful in moderating the growth of total spending. Total spending expanded at a rapid 9.4 per cent rate from mid-1967 to mid-1968. After imposition of the surtax and some Government spending cuts in

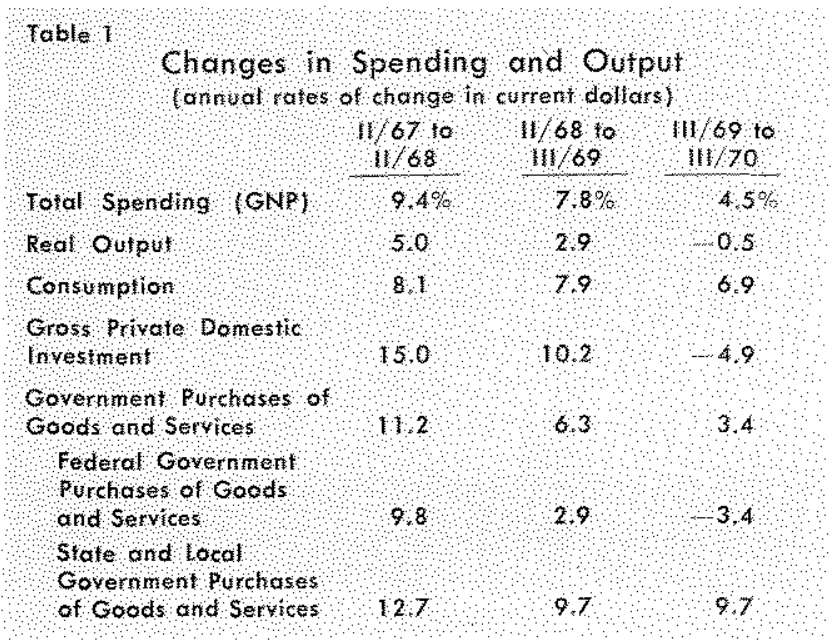

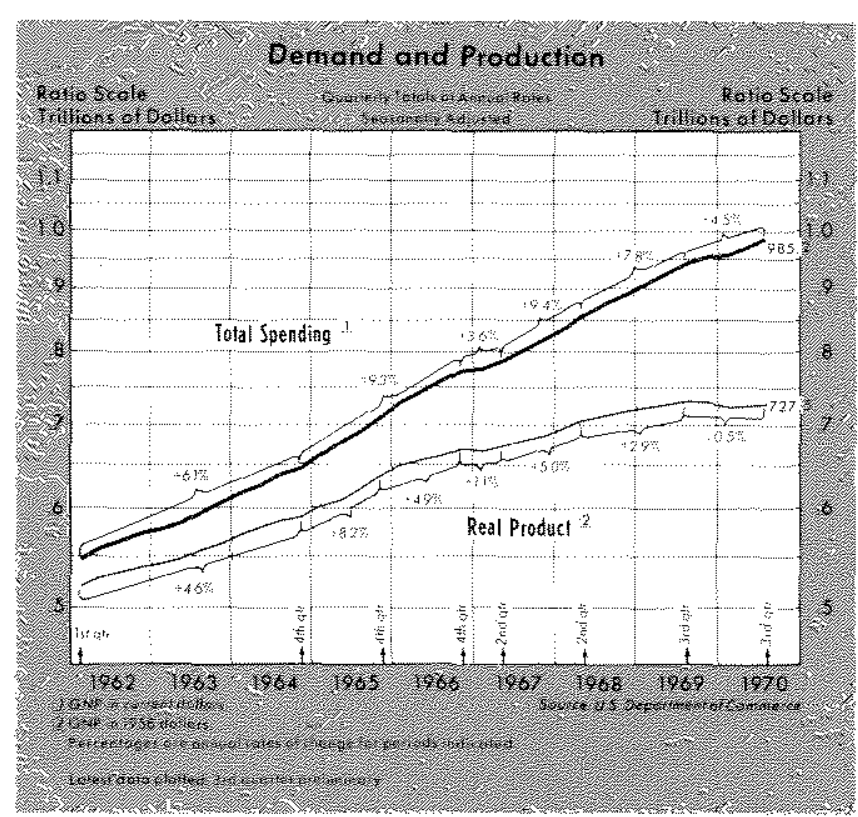

mid-1968, spending grew at a slower, but still rapid, annual rate of 7.8 per cent intil the third quarter of 1969. Following reduced monetary expansion beginning in early 1969, spending slowed to a more moderate 4.5 per cent rate of increase from the third quarter of 1969 to the third quarter of 1970 , a rate slightly highet than the commonly assumed trend growth of productive capacity (Table 1).

Growth in real output slowed simultaneously with the reduction of total spending. The unsustainable 5 per cent increase of real output from mid-1967 to mid-1968 slowed to about a 3 per cent annual rate from mid-1968 to the third quarter of 1969 , and then to a 0.5 per cent decline from the third quarter of 1969 to the third quarter of 1970 .

Within the private sector, the reduction in spending growth in the last two years was greater in investment expenditures than in consumption. Consumer spending growth slowed gradually to a 6.9 per cent rate in the last year. The trend of gross private domestic investment changed sharply, slowing from a 15 per cent rate of expansion from the second guarter of 1967 to the second quarter of 1968 , to a 10 per cent annual rate from the second quarter of 1968 to the third quarter of 1969 , and then to a 4.9 per cent rate of decline from the third quarter of 1969 to the third quarter of 1970 (Table 1). The initial absolute decline in investment expenditures occurred about two quarters after monetary restraint was initiated and simultaneously with early adjustments in total spending. The decline was comparable to investment behavior at the end of 1966 and the beginning of 1967. 


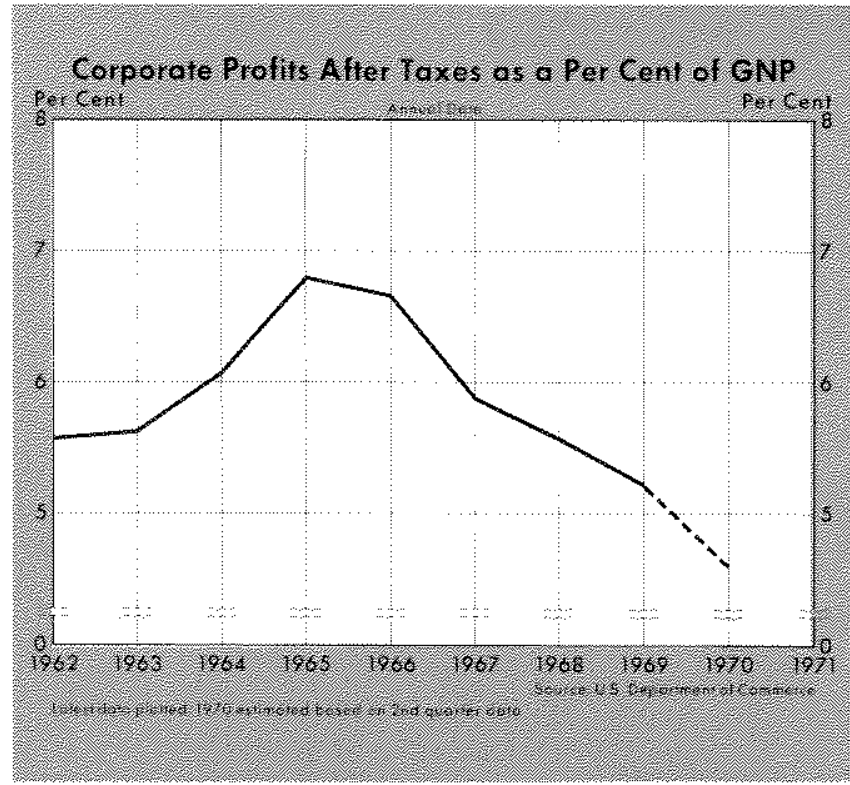

Corporate profits after taxes, a major source of investment funds, responded sharply to reduced total spending and the continued rise in costs. They declined 12 per cent from the second quarter of 1969 to the second quarter of 1970 after showing little net change in the previous three years. Profits declined from 6.8 per cent of GNP in 1965 to 5.2 per cent in 1969 and to 4.6 per cent in the first half of 1970 .

Purchases of the public sector have also grown more slowly in the last two years, and priorities have been shifted. Total government purchases (Federal, state, and local) have grown at about a 5 per cent annual rate since mid-1968, compared with about a 14 per cent rate from 1965 to 1968 . The trend of Federal Govemment purchases has shifted most markedly, remaining about unchanged since mid1968 after growing at a 14.8 per cent annual rate from mid-1965 to mid-1968. State and local government purchases have grown at about a 9.7 per cent annual rate since mid-1968, compared with a 13 per cent rate in the preceding three years.

Defense purchases have been cut back severely, while nondefense purchases of the Federal Government have continued to grow. Recently, defense spending has been about $\$ 2.4$ billion lower than at its peak at the end of 1968, and 14 per cent fewer people are currently employed in defense and defense-related industries than in mid-1968. Defense spending rose from 8.5 per cent of total spending (GNP) in the 1962-64 period to about 9 per cent at the peak in $1967-68$, and has since declined to 7.6 per cent in the third quarter of 1970 .

\section{Emploument}

Employment responded only slowly to reduced growth in spending and output. Payroll employment growth slowed slightly in the last half of 1969 but nonetheless continued to grow strongly through March of 1970 , before declining at a 2.4 per cent rate from March to September. In 1969 and early 1970 firms adjusted mainly overtime and hours of work rather than reduce their trained labor force. Reduced spending and production since last spring have forced employers to reduce their labor force. Despite recent declines, however, employment relative to population of working force age (16-64) was higher this past summer than at any time in the Fifties or the Sixties before 1967.

The unemployment rate averaged 5.2 per cent in the third quarter of this year compared with 3.6 per cent a year earlier. The recent 5.2 per cent rate compares with an average of 5.8 per cent in 1961-64 when prices were not rising significantly. The unemployment rate for married men in the third quarter of this year was 2.8 per cent compared with 1.6 per cent a year earlier and an average of 3.6 per cent in 1961-64.

\section{prices}

Price trends over a considerable period of time generally reflect the trend of spending relative to the trend of productive capacity. Many prices, however, are slow to change, and hence overall prices do not move up quickly when spending growth accelerates, nor stop rising soon after the growth in spending moderates. Restrictive monetary actions of 1969 and early 1970 have been sufficient to halt the acceleration of inflation, and there are scattered indications that the rate of inflation may be slowing.

Consumer price advances may have moderated since last April. From April to August, consumer prices rose at a 4.5 per cent annual rate, compared with a 6 per cent rate in the preceding year. The decline in recent months has been the result of a less rapid rise in the prices of services and food. Although these data suggest that the rate of consumer price advance may be slowing, it is difficult to say at this time whether this constitutes the beginning of a definite change in trend or is merely an irregularity in the series. Such an irregularity occurred in farm products and food prices in the summer of 1969.

Wholesale prices of industrial commodities rose at a 2.1 per cent annual rate from May to September, compared with a 3.9 per cent rate in the preceding year. While these developments are encouraging, sim- 


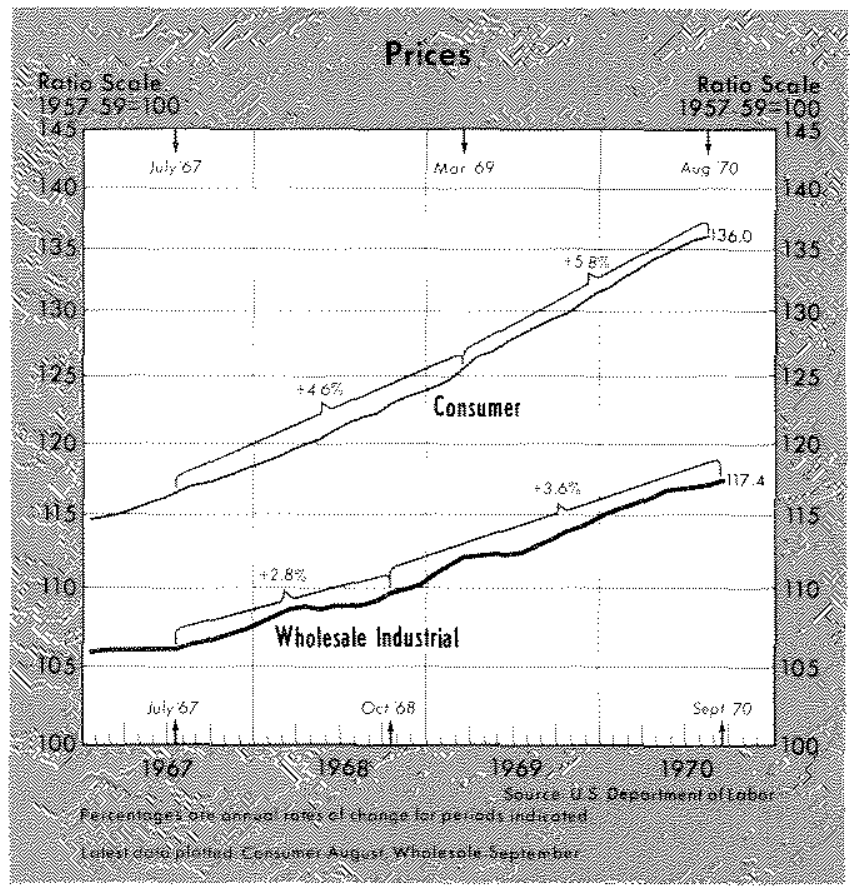

ilar consecutive months of improvement in industrial prices in 1969 did not prove to be lasting. Probably the most significant improvement in wholesale prices in 1970 has been the lessening of upward price pressures in the markets for metals. An additional grouping of wholesale prices, the daily spot market index of thirteen raw industrial prices which are believed to be highly sensitive to demand conditions, has declined sharply since February of this year. The index reflects world as well as domestic market conditions.

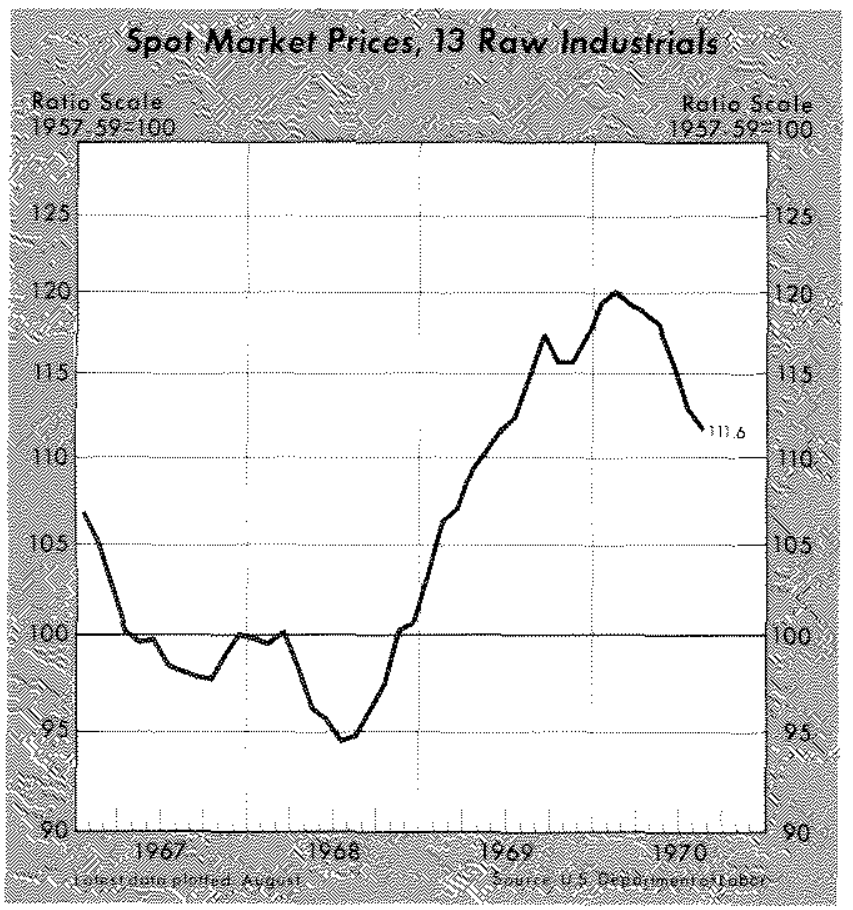

One reason for some optimism regarding price prospects in the near future, despite only uncertain improvements so far, is that growth in total spending has remained moderate for over a year. Past experience indicates that changes in spending growth have usually affected output initially, and about three quarters after the reduction in spending and output, a reduction in the rate of inflation has generally become evident. Since monetary restraint was initiated in early 1969, and did not materially reduce spending until the last half of 1969, the lags in price adjustments have not been unexpectedly long, especially in view of the strong upward price momentum which had developed. An increasingly larger impact on prices can be expected as the period since the onset of restraint lengthens, provided stimulative stabilization policies are not pursued too actively.

\section{Thfartomary Expochens and Monetary Policy}

The course of total spending is influenced primarily by monetary and fiscal actions. Inflationary expectations, which are formed and dissipated only slowly, have their main effect on the division of total spending between prices and real output. Some of the inpact of inflationary expectations since mid-1969 has been manifested in a slowing of real output growth.

Inflationary expectations continue to have a bearing on the formulation of monetary policy. Monetary authorities are currently faced with five years of cumulated inflationary expectations. Monetary actions to combat inflation must now be sufficiently strong to break the pattem of inflationary expectations if the ground work is to be laid for resumed real growth with relative price stability.

A vital current question is whether the slowing of real output growth from mid-1968 through mid-1969 and then three or four quarters of no expansion in late 1969 and in 1970 has been sufficient to reduce inflationary expectations adequately. The more expansion" ary monetary actions thus far in 1970 may contribute to real output growth and greater employment, and probably do not run a risk of fostering a growth of total spending which reinforces inflationary expectations. But significantly more rapid monetary expansion than has prevailed so far in 1970 , if continued for any length of time, is likely to prolong the inflation problem unduly. Total spending growth must be appropriately limited if we are to complete within a reasonable period the transition to an economy of relative price stability. 